
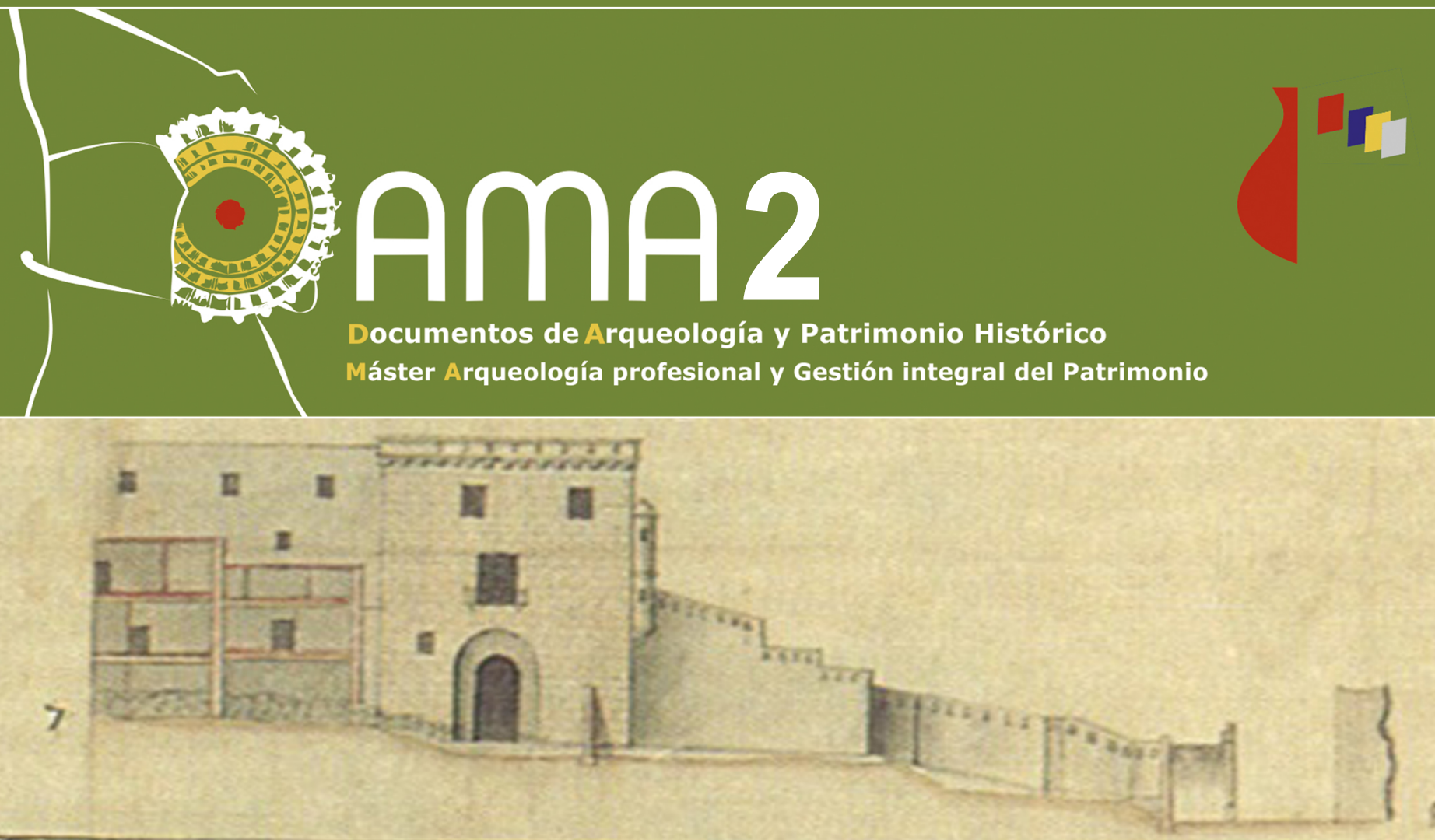

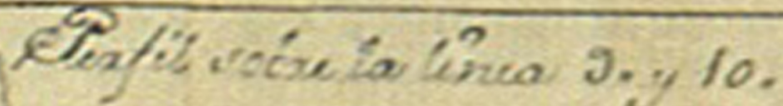

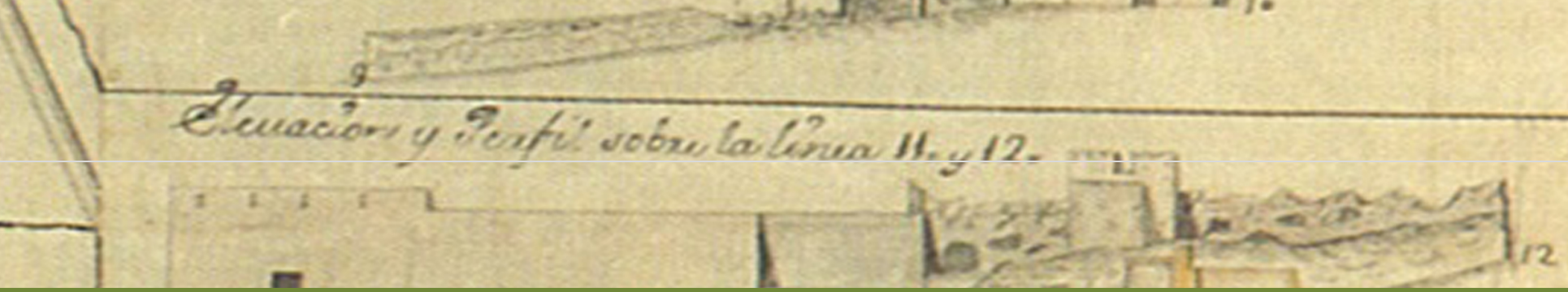

\title{
Documentos de Arqueología y Patrimonio Histórico
}

Revista del Máster Universitario en Arqueología Profesional y Gestión integral del Patrimonio 



\section{DAMA 2}

\section{7}

DOCUMENTOS DE ARQUEOLOGÍA Y PATRIMONIO HISTÓRICO DEL MÁSTER UNIVERSITARIO EN ARQUEOLOGÍA PROFESIONAL Y GESTIÓN INTEGRAL DEL PATRIMONIO DE LA UNIVERSIDAD DE ALICANTE 


\section{ÍNDICE}

EDITORIAL

Gabriel García Atiénzary Fernando Prados Martínez (Coordinadores del máster)

\section{ARQUEOLOGÍA Y MÉTODO}

LA DESAPARICIÓN DE LOS NEANDERTALES EN LA PENÍNSULA IBÉRICA.

ANÁLISIS CRÍTICO DE LA BIBLIOGRAFÍA

Alejandro Mayor Benadero.

LA VAJILLA CERÁMICA DEL YACIMIENTO NEOLÍTICO DE LIMONEROS II-III (ELCHE, ALICANTE)

Silvia Martínez Amorós

LOS PROCESOS DE MANUFACTURA DE PLAQUETAS RETOCADAS DE SÍLEX DEL III MILENIO CAL BC EN EL LEVANTE DE LA PENÍNSULA IBÉRICA A TRAVÉS DE LA TECNOLOGÍA LIITICA EXPERIMENTAL

Francisco Morales Tomás

ESTUDIO COMPARATIVO DE LAS VILLAS ROMANAS EN VARIAS REGIONES DE HISPANIA (III-V): ANÁLISIS SINTÁCTICO ESPACIAL. HACÍA LA OBTENCIÓN DE MODELOS

Rubén Santana Onrubia

MADINNAT AL-LAQANT, ESTUDIO DEL URBANISMO ISLÁMICO DE LA CIUDAD DE ALICANTE Raquel Bujalance Silva

\section{GESTIÓN Y PUESTA EN VALOR DEL PATRIMONIO}

CONFORMACIÓN DE UNA INSTITUCIÓN. DE LA COLECCIÓN MUSEOGRÁFICA CASA “EL CISCO" AL MUSEO HISTÓRICO DE ASPE.

María T. Berná García

ROLES IDENTITARIOS A TRAVÉS DE LA FOTOGRAFÍA EN ALICANTE A MEDIADOS DEL SIGLO XIX Y PRINCIPIOS DEL SIGLOXX

Yara M. Santacruz Carmona

CRÓNICA DEL IX CONGRESO DEL MÁSTER EN ARQUEOLOGÍA DE LA UNIVERSIDAD DE ALICANTE

Carolina Doménech Belda, Ignasi Grau Mira 



\title{
ESTUDIO COMPARATIVO DE LAS VILLAS ROMANAS EN VARIAS REGIONES DE HISPANIA (III-V): ANÁLISIS SINTÁCTICO ESPACIAL. HACÍA LA OBTENCIÓN DE MODELOS
}

\author{
Rubén Santana Onrubia
}

\section{RESUMEN}

El presente trabajo estaría enmarcado dentro del estudio de la arquitectura doméstica. Ubicándonos en el Bajo Imperio, estudiaremos a través de la sintaxis espacial las villas monumentales de tres zonas de Hispania: La Meseta, la Costa de la Tarraconense, y por último, el Valle del Ebro. Este estudio se realiza con una doble finalidad. Por un lado, pretendemos extraer diversas conclusiones y ver si podemos establecer modelos de villas para el marco geográfico estudiado. Por otro lado, el segundo objetivo de este trabajo sería el de estudiar las posibilidades que nos ofrece una metodología como la sintaxis espacial, así como sus limitaciones.

Palabras clave: Villa, Imperio Romano, Sintaxis espacial, Arquitectura doméstica, Monumental.

\begin{abstract}
This work would be framed within the study of Domestic Architecture. We study the Late Empire through space sintax. Each other study the villas in three areas of Hispania: La Meseta, the Tarraconese coast, and finally, the Ebro Valley. This study was performed with a dual purpose. On the one hand, we intend to draw different conclusions, and see if we can establish models of villas to the geographical context studied. On the other hand, the second objective of this work would be to study the possibilities offered by a methodology such as space syntax as well as their limitations.
\end{abstract}

Keywords: Villa, Roman Empire, Space syntax, Domestic Architecture, Monumental. 


\section{APROXIMACIÓN CONTEXTUAL}

El presente estudio emana de nuestro Trabajo Fin de Máster "Estudio comparativo de las villas romanas en varias regiones de Hispania (III-V): análisis sintáctico espacial". Esta síntesis ha sido depurada y en ella se presentan los principales resultados de un largo estudio acerca de la aplicación de la sintaxis espacial en villas romanas bajoimperiales. Durante el siglo III d.C. tenemos un cambio radical en el Imperio Romano, esta serie de transformaciones se evidencian también en la realidad socioeconómica del Imperio, reorganizándose desde las estructuras de producción hasta los diversos circuitos comerciales (Bravo, 2013). Este hecho unido a la reducción drástica en los grandes programas edilicios en las principales ciudades de Hispania tuvo como consecuencia la ruralización generalizada en la mayoría de la Península Ibérica (Uribe, 2008: 517). El reflujo de las élites hacia el mundo rural hizo que el paisaje rural en Hispania gozase de una creciente vitalidad a lo largo de la Antigüedad Tardía, teniendo su reflejo en el máximo exponente de dicho paisaje: las grandes villas.

Antes de avanzar en este trabajo debemos apuntar una serie de cuestiones vitales que constriñen nuestro estudio. Si bien es cierto que es abundante el número de publicaciones acerca de las villas romanas en las diversas zonas de estudio en las que se enmarca este ejercicio, dichas publicaciones presentan un carácter bastante asimétrico y desigual, tanto por sus planteamientos, como por su metodología y resultados. Este hecho es un factor determinante a la hora de tratar de realizar un trabajo que exceda del ámbito de lo estrictamente regional, y que pretenda encontrar modelos globales, tal y como se pretende extraer tras este análisis.

Como ya hemos mencionado, durante la época bajoimperial en Hispania vemos como el paisaje rural romano goza de una gran vitalidad. Este proceso, pese a que cristalizará a lo largo del siglo III d.C., alcanzando sus máximas cotas durante el siglo IV d.C., hunde sus raíces en la época de Augusto. Desde mediados del siglo II d.C. vemos en Hispania un proceso de reducción progresiva del número de ciudades en favor de una mayor centralización funcional urbana que en consecuencia desembocará en una mayor ruralización de la sociedad romana (Burillo, 2007: 420). Poniendo el foco en el marco cronológico en el cual nos situamos, III-V d.C., teniendo en cuenta los datos que el registro arqueológico nos ofrece y el estado actual de la investigación, vemos como tenemos diversos tipos de hábitat dentro de lo que definimos como poblamiento rural: vici, castella, pagi, casae, tuguria, o, las villae, serán los principales tipos. En la actualidad, de entre todos estos tipos de asentamientos rurales, las villas romanas han sido las más estudiadas y las que más información han aportado, desde el registro arqueológico, al estudio de la época bajoimperial (Chavarría, 2006: 20). Pese a que la implantación del modelo de villa en Hispania se remonta a época tardorrepublicana, será durante el siglo III d.C. cuando se lleve a cabo la monumentalización de un número significativo de las mismas, mediante el empleo de programas decorativos y la anexión de termas a la pars urbana de la villa (Chavarría, 2006: 21). Por lo tanto, como se ha señalado últimamente en numerosos estudios, la caracterización del siglo III d.C. en Hispania como el siglo de la destrucción de numerosas villas romanas a consecuencia de las diversas invasiones fue matizado, en la década de 1980, a la luz de los datos que nos ofrece el registro 
arqueológico (Brogiolo y Chavarría, 2008: 196-198). En algunas zonas de Hispania, como puede ser La Meseta, al igual que sucede en otras partes del Imperio, los siglos III y IV d.C. serán los siglos de mayor esplendor en cuanto a la arquitectura residencial rural se refiere (Chavarría, 2006: 2-23). Este hecho puede constatarse de forma aún más incisiva en dos de las tres zonas que estudiaremos en este ensayo: el Valle del Ebro y la zona de la Meseta (Chavarría, 2007).

Las tres zonas elegidas para nuestro estudio son: la Meseta, la costa de la Tarraconense -desde el Cabo de las Huertas hasta el Cap Sa Sal- , y por último, el Valle del Ebro, presentando en esta síntesis los 10 casos más significativos (fig. 1).

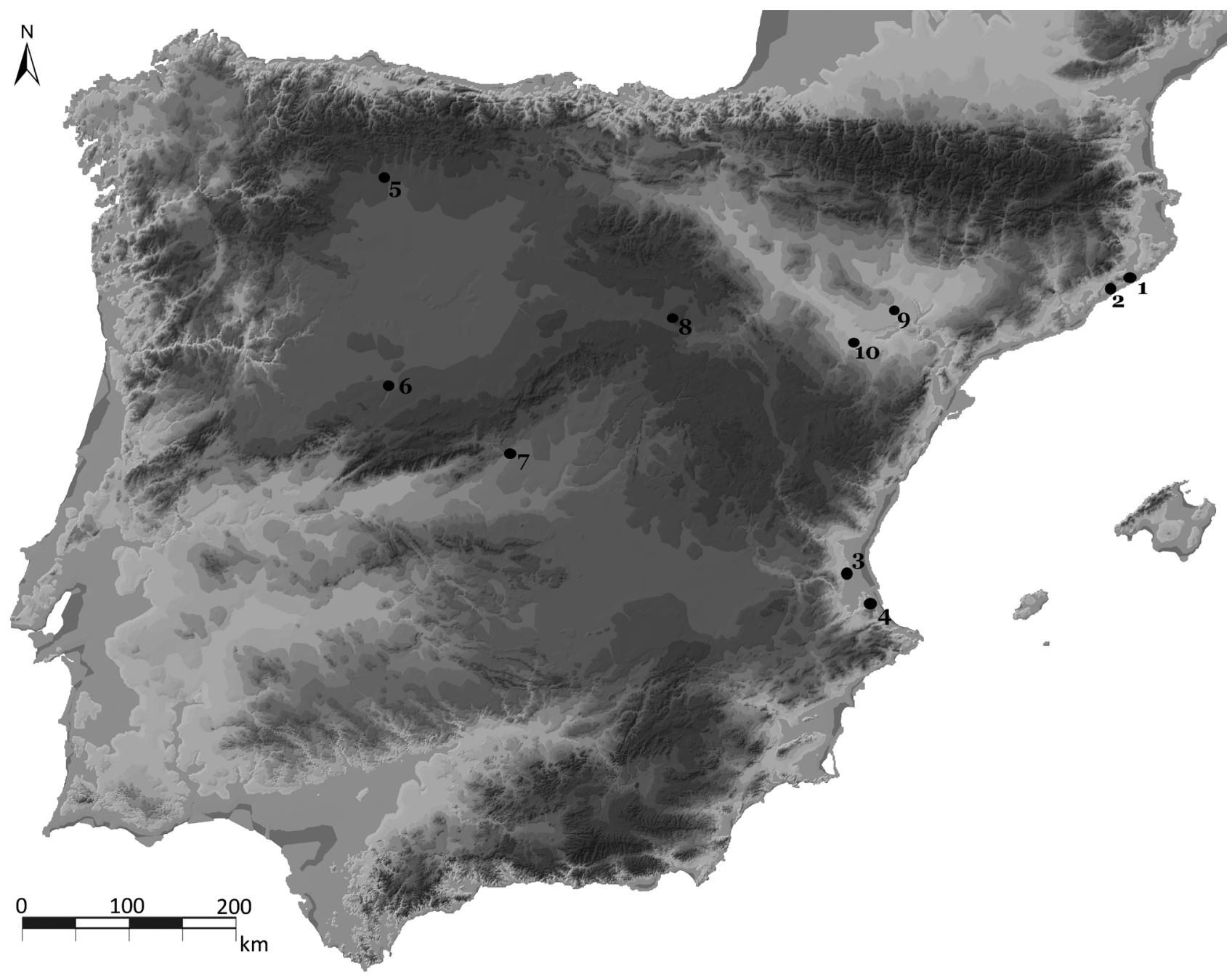

Fig. 1. Mapa físico de la Península Ibérica con la localización de los yacimientos estudiados en este trabajo. 1: Torre Llauder (Barcelona); 2. Horta Farrerons (Barcelona); 3. Pou de la Sargueta (Valencia); 4. Cornelius (Valencia); 5. La Olmeda (Palencia); 6. Almenara de Adaja (Valladolid); 7. La Torrecilla (Madrid); 8. La Dehesa (Soria); 9. Fortunatus (Huesca); 10. La Malena (Zaragoza).

La elección de estos enclaves no ha sido aleatoria. Ya que realizar un estudio de todas las villas monumentales de Hispania hubiera excedido el ámbito requerido para una investigación de estas 
características, pudiendo llegar incluso a abarcar las dimensiones de una investigación propia de una tesis doctoral, se ha optado por elegir tres conjuntos geográficos, representativos y bien diferenciados, que se insertan de forma desigual en la realidad socioeconómica del Imperio Romano. Si bien es cierto que durante época altoimperial la zona más relevante, desde un punto de vista estrictamente económico, debido a su inmersión en los circuitos comerciales ultramarinos, fue la costa de la Tarraconense, posteriormente con el reordenamiento socioeconómico del siglo III d.C. dicha zona será la más afectada. Este hecho podremos observarlo en la magnitud de las villas de la zona, ya que no presentan la misma entidad que podemos observar en las villas de La Meseta o el Valle del Ebro.

\section{ARQUITECTURA DOMÉSTICA Y LECTURA SOCIAL DEL ESPACIO}

Antes de abordar el corpus metodológico del presente trabajo se ha creído necesario esbozar unas nociones teóricas básicas acerca de la arquitectura doméstica. Para poder conocer y evaluar realmente la profundidad de la implantación del poder político en una sociedad como la romana no solo debemos analizar los elementos públicos o excepcionales de la vida de los miembros del Imperio, como pueden ser las festividades, los cultos, o los monumentos cívicos, entre otros, sino que también debemos evaluar la capacidad de permeabilidad en ámbitos mucho más cotidianos (Bermejo, 2014: 16). Es desde este punto de arranque del que partimos para justificar el análisis de las villas durante el Bajo Imperio, como espacios domésticos en auge ante el estancamiento que comienzan a sufrir las estructuras económicas estatales. Partiendo de los postulados teóricos generales que rigen el estudio de la arquitectura doméstica como ente social producto y reflejo de las élites debemos ver cómo nos aproximamos al uso social del espacio. Para ello partiremos de la obra de Vitrubio, yendo a la definición que nos ofrece de Arquitectura como "el arte de proyectar y construir edificios". En esta definición se encuentra presente la clave para la lectura arqueológica del uso social del espacio: el binomio conformado entre el proyecto y la construcción. Mientras que el proyecto se enmarca dentro del plano abstracto ideal, la construcción forma parte del plano material. La arquitectura doméstica es la herramienta que utilizamos para entender la relación que se establece entre las dos caras que conforman este binomio, en el que la mayor dificultad reside en el entendimiento del alcance del significado en lo referente al plano ideal del diseño (Hillier, 1996: 10-38).

En cuanto a los diferentes autores que han tratado de ofrecer un programa teórico sobre la concepción del espacio en el marco de las sociedades humanas que de una clara respuesta a cómo operan entre sí el plano teórico y el plano material, tenemos a Raporport (1982), a Foucault (1984), o a Lefebvre (1991), entre otros. Una de las bases sobre las que todos estos autores asientan sus programas teóricos es la capacidad de las estructuras sociales, y consecuentemente de la clase social que las controlan, para establecer lenguajes espaciales propios. Estos lenguajes arquitectónicos reflejarían determinadas concepciones ideológicas y económicas que subyacen en el contenido semántico de los espacios construidos (Bermejo, 2014: 83). Respecto a los postulados anteriores, que comparten los autores citados, Lefebvre va un poco más allá conectando la adaptación de los códigos y funciones de los espacios arquitectónicos a la evolución histórica de los medios de producción (Bermejo, 2013). En 
su principal trabajo, The Production of Space, Lefebvre (1991) plantea tres grandes momentos para el cambio en la articulación de los espacios constructivos en el mundo occidental: el mundo antiguo, el feudalismo, y por último, el capitalismo, partiendo de la base de la concepción materialista de la historia emanada de los textos de Marx y Engels (1962: 252-268 cit. Lefebvre, 1991: 109). Cada uno de estos sistemas productivos tendría como consecuencia la producción de un orden espacial determinado, premeditado, y fruto de los objetivos de la clase dominante en el momento histórico concreto. Los cambios espaciales entendidos como parte de un aparato ideológico emanado del poder controlado por el grupo social dominante, reflejaría y reforzaría los cambios en la estructura de los poderes económicos y sociales, lo que generará nuevos productos arquitectónicos (Bermejo, 2014: 83).

Por lo tanto, cuando somos conscientes de esta dimensión de la Arquitectura, es cuando podemos comenzar a estructurar las relaciones de poder que subyacen bajo ella, y su estudio a través, en nuestro caso, del registro material. En la medida en que la Arquitectura es una técnica destinada a la creación de espacios para regular las actividades y relaciones sociales de los seres humanos, es considerable el poder de aquellos que diseñan y proyectan los modelos constructivos. Lógicamente estos diseñadores se encuentran impregnados por el marco normativo conductual del espacio en el que se han socializado, sin embargo, no debemos entender el edificio resultante como el resultado de una relación unidireccional, sino más bien como el producto de varias relaciones dialécticas y asimétricas, como puede ser la relación arquitecto/visitante, o la relación habitante/visitante (Lefebvre, 1991: 114). Si aceptamos la existencia de las relaciones que subyacen bajo la empresa arquitectónica, implícitamente estamos dando por válidas dos premisas: en primer lugar, estamos admitiendo que la condición material de las construcciones domésticas nos permite trascender del ámbito discursivo en el que se ha codificado la teoría arquitectónica de la Antigüedad; y en segundo lugar, y conectada a la anterior premisa, estamos admitiendo que podemos medir el grado de implantación de las normas sociales asociadas a determinados modos de producción espacial (Bermejo, 2014: 85).

Ahora bien, en el cómo vamos a trascender del plano meramente teórico al desarrollo de una herramienta analítica para la Arquitectura que nos permita leer el uso social del espacio a través del estudio de los restos materiales del pasado es donde reside la innovación que aporta la sintaxis espacial a la household archaeology. La teoría vitrubiana nos muestra los modelos sociales o culturales ideales que rigen el diseño de los edificios de época imperial, sin embargo, no nos ofrece ninguna herramienta para poder comprobar el nivel de implantación en cada caso concreto. Por lo tanto un análisis de un espacio construido exclusivamente vitrubiano nos mostrará únicamente la cercanía o lejanía de dicho espacio con respecto a su modelo ideal, dejando al margen todo aquello que sea diferente a esa idealización. Este hecho hace necesario el buscar teorías analíticas complementarias para el análisis social y cultural de la arquitectura doméstica (Bermejo, 2013: 142). Todo ello ha llevado a algunos arquitectos a desarrollar una serie de métodos analíticos con los que poder registrar y cuantificar algunas de las relaciones socio-estructurales que subyacen en la distribución espacial 
de los conjuntos arquitectónicos, siendo la sintaxis espacial uno de los mejores métodos (Hillier y Hanson, 1984). La sintaxis espacial es el conjunto de reglas combinatorias que rigen la estructuración espacial de un conjunto arquitectónico concreto que nos permite registrar las dinámicas sociales que subyacen en la configuración de los entornos construidos (Grahame, 2000: 25). Para entender más concretamente qué dinámicas sociales podemos registrar gracias al empleo de esta herramienta metodológica debemos profundizar en este aspecto más allá de lo que nos ofrece la somera definición del término, y analizar los cálculos matemáticos sobre los que se sustenta.

\section{METODOLOGÍA}

\subsection{Sintaxis espacial}

Ante la duda generada a la hora de buscar métodos de análisis que permitan a los arqueólogos registrar la influencia de las dinámicas sociales en la configuración espacial de las viviendas en época romana a partir de la inferencia de los restos materiales la sintaxis espacial plantea como mínimo una serie de respuestas que pueden incorporarse a estudios de carácter más amplio de forma satisfactoria. Podríamos definir la sintaxis espacial como un modelo analítico destinado a cuantificar, a través de la aplicación de cálculos matemáticos, y representar, mediante el empleo de múltiples herramientas gráficas, las formas de relación social que subyacen en la producción espacial de los entornos construidos (Hillier y Hanson, 1984: 82-83). Aunque este conjunto de métodos y técnicas está diseñado para su uso en el campo de la Arquitectura, recientemente se ha aplicado con bastante éxito en la lectura arqueológica. La sintaxis espacial permite no solo registrar sino también cuantificar con precisión algunas dinámicas sociales implícitas en los edificios, que a través de los medios tradicionales de representación planimétrica son difícilmente accesibles (Bermejo, 2013: 144). Por lo tanto esta metodología que nos vincula y organiza los espacios de un conjunto arquitectónico, tratando de inferir aquellos aspectos de la estructura social que pudieron influir en su diseño, nos permite registrar el grado de jerarquización que opera en la configuración espacial de un ámbito concreto (Bermejo, 2009: 52). Sin embargo, como cualquier conjunto de métodos y técnicas posee sus limitaciones, a la hora de inferir el tipo de estructura social que habitó en el entorno constructivo analizado.

Con tal de minimizar el impacto de estas limitaciones es necesario aclarar dos puntos previos para poder entender los fundamentos que nos permitan aplicar la sintaxis espacial de forma correcta. En primer lugar, debemos entender que la célula espacial, o Unidad Espacial, será la unidad fundamental del análisis. La idea de célula espacial parte del concepto de límite como elemento separador, destinado a definir un espacio y segregarlo de aquello que denominaremos espacio indiferenciado, o espacio exterior (Hillier y Hanson, 1984: 144). La segunda premisa que debemos tener clara antes de abordar un análisis sintáctico-espacial parte de la consecuencia lógica de la afirmación de la primera: si la unidad fundamental es la célula espacial el grado de accesibilidad dependerá del número y naturaleza de permeabilidad de esta célula con respecto a otras unidades espaciales. Este 
hecho implicaría que el espacio construido tiene un significado social concreto en función de su orden interior interrelacionado. Esta ordenación parte y se reproduce a partir de un modelo particular de permeabilidad que se caracteriza por la yuxtaposición de diversos espacios con diferentes niveles de presencia o accesibilidad (Bermejo, 2009: 51).

\subsection{Herramientas existentes para la aplicación de un análisis sintáctico espacial: índices de valor numérico}

En cuanto a los índices de valor numérico que se extraen de la aplicación de la sintaxis espacial, principalmente desarrollados por Hillier y Hanson (1984: 17-29), su finalidad es mesurar o cuantificar las relaciones sintácticas.

Estas relaciones sintácticas se basarán en los gráficos de accesibilidad debidamente justificados a partir del espacio exterior. Para el presente trabajo se han comprobado manualmente un número de casos representativo para ver que el software utilizado para la elaboración de los gráficos de accesibilidad funciona correctamente. El programa empleado, llamado AGRAPH, fue desarrollado por el arquitecto noruego B. Manum (2005) con la intención de hacer accesible de forma gratuita una herramienta que permitiese trabajar de forma digital en el campo de la sintaxis espacial.

El primero de los índices es útil para medir las relaciones que operan entre una unidad espacial y el resto de las unidades de su mismo entorno construido. Este índice cuantitativo que nos permite identificar espacios significativos en el dominio de la accesibilidad a espacios adyacentes es el que conocemos como control value -CV-, o valor de control (Bermejo, 2009: 54). El cálculo del CV de un espacio se determina contando el número de espacios con los que este tiene una conexión directa, en una relación en la que cada uno de los espacios da a su vecino adyacente $1 / \mathrm{n}$ de su "control". El CV de un determinado espacio será la suma de todos los valores fraccionales de cada uno de sus vecinos (Bermejo, 2013: 149). Para comprender más fácilmente mostraremos los cálculos de un supuesto hipotético de un edificio al que se accede desde el exterior (fig. 2), espacio indiferenciado, a través de una habitación -Habitación 1-, y esta conecta a su vez de forma individual con otras 5 habitaciones -Habitación 2, 3, 4, 5 y 6-.

Vemos como la Habitación 1 ofrece a cada uno de sus vecinos un valor de control de $1 / 6$, mientras que el resto de habitaciones junto con el espacio exterior confieren a la Habitación 1 un CV

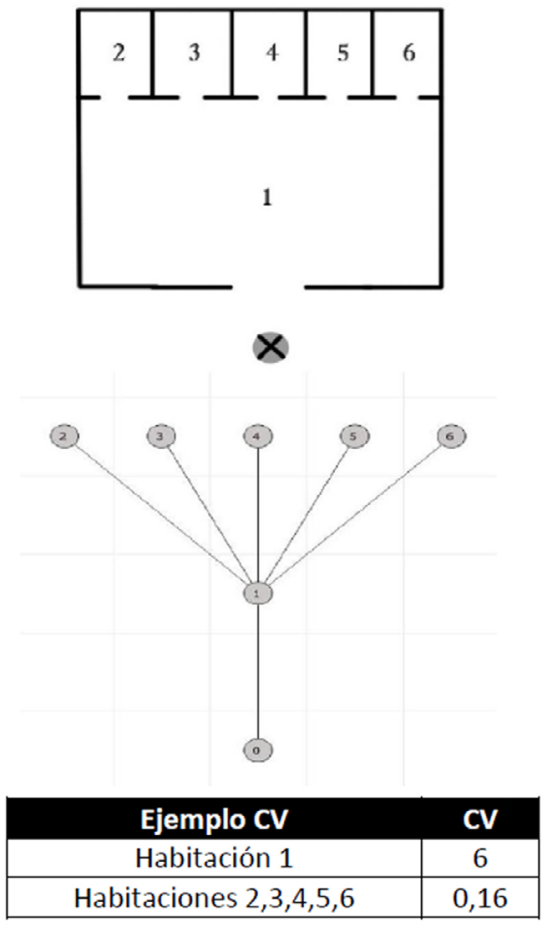

Fig. 2. Planimetría, gráfico de accesibilidad y cuadro de resultados de un supuesto hipotético para el cálculo del CV (Elaboración propia). 
de 6. Los valores de control elevados, como los que podemos encontrar en determinados espacios de los gráficos de accesibilidad tipo radial-panóptico, se corresponden con espacios controladores, mientras que los que muestran un bajo valor de control se corresponden con espacios controlados.

Otro índice numérico es el conocido como relative asymetry, RA, y nos sirve para medir la relación entre la accesibilidad de un espacio y el principio matemático de la simetría-asimetría (Bermejo, 2009: 55). Un espacio más simétrico debe tener un gran número de relaciones similares, lo que implica que un determinado número de límites deben ser cruzados para acceder a él, la fórmula matemática que rige esta relación es la siguiente: . En la ecuación anterior $M D$ se correspondería con mean depth, o distancia relativa, entre el espacio indiferenciado, exterior, y la unidad espacial analizada (Hillier y Hanson, 1984). Para su cálculo asignamos un valor de profundidad, depth, a cada uno de los espacios que deseamos analizar en función del número de espacios que se deben cruzar para acceder a él desde el espacio exterior. El valor de profundidad lo dividimos entre el número de unidades espaciales y le restamos uno -el espacio exterior-, y de esta forma obtendremos la distancia relativa de cada unidad. Por último, es necesario aclarar que el valor k, que aparece en la ecuación raíz para el cálculo de la RA, es el número total de espacios reflejados en el gráfico de accesibilidad, es decir, todas las unidades espaciales más el espacio indiferenciado (Bermejo, 2013: 145-146). Para poder hablar de cierta asimetría debemos tener una desviación estándar superior al 0,5-1. Si los espacios no presentan diferencias significativas entre sus valores de RA tenemos detectado analíticamente un patrón de convivencia espacial bastante estrecho entre todos los componentes del edificio residencial, ya que los componentes de la vivienda se ven obligados a compartir espacios. Por lo tanto, niveles bajos de RA indican una capacidad para separar o segregar ambientes reducida (Bermejo, 2013: 147). Esto aplicado al mundo romano podría hablarnos de la forma de convivencia entre el servicio doméstico y dueños en función de la capacidad de segregación de un dominus en su residencia. A su vez, poca segregación espacial implica un estrecho marco de vigilancia mutua entre todos los miembros de la vivienda. Esta vigilancia se ejerce por un lado, por parte del dominus sobre los omnipresentes miembros del servicio doméstico, y por otro lado, entre los habitantes permanentes de la vivienda y los huéspedes o invitados. Frecuentemente cuando existe poca divergencia entre los valores de RA de un entorno construido existe un espacio, como mínimo, con un gran CV. Este hecho nos indica que cuando más convivencia existe más control se requiere. Por el contrario, si tenemos una mayor diferenciación entre los valores de RA lo que nos está indicando es que los miembros de las élites, en la medida en que controlan la residencia, poseen una mayor capacidad para escapar a los marcos de convivencia espacial (Bermejo, 2014: 105-107).

El ejercicio de transcripción de los datos sintáctico espaciales a un contexto histórico determinado es donde, a nuestro juicio, reside la clave para el futuro desarrollo de estos estudios. Si no cubrimos el esqueleto formado por los valores numéricos con un buen músculo de interpretaciones históricas coherentes, el cuerpo de nuestra investigación para la lectura social de los espacios domésticos estará incompleto. Si se realiza un buen trabajo de interpretación, los datos aportados por la sintaxis espacial, 
preferiblemente complementados con otros datos empíricos, nos pueden hablar de aspectos sociales realmente interesantes. Ya hemos visto como con la comparación de los datos de RA y CV podemos ver si existe o no una jerarquización interna muy grande en los entornos construidos o si estamos ante una estructura de hábitat simple o compleja, entre otras cuestiones. También podemos emplear los datos cuánticos extraídos para vislumbrar diversos aspectos sociales, comparando estos datos con la existencia de diversas fases en los entornos construidos estudiados, con el número aproximado de personas por unidad doméstica, o comprobando mediante un análisis diacrónico si el área residencial va aumentando como consecuencia de un posible éxodo rural. A su vez, podemos abordar espacios como los atrios desde una nueva perspectiva como núcleos controladores del ámbito residencial, más allá de las atribuciones tradicionales que se le concedían a este espacio.

\section{PRESENTACIÓN DE RESULTADOS DEL ESTUDIO}

\subsection{Modelos de villas}

Tras el estudio de villas que presentaremos a continuación se han conseguido extraer dos modelostipo que caracterizan las villas monumentales, en cuanto a su configuración espacial se refiere, abarcando el marco cronológico descrito anteriormente, del III d.C. al V d.C., en las tres zonas de estudio escogidas. El primero de estos modelos, que enunciaremos en este trabajo como Modelo A, es el denominado como modelo protopanóptico. Este patrón espacial se caracteriza por tener un espacio con un elevado CV -Valor de Control- respecto al resto de espacios, y que suele situarse en el centro del entramado constructivo. Además este espacio funciona como centro articulador del resto de estancias. Esta sería la característica principal del Modelo A, aunque, también tenemos otras características que agrupadas terminan de definir este modelo: elevados índices de convivencia espacial entre los miembros de la unidad doméstica, no existen grandes diferencias entre los valores de RA -Asimetría Relativa- de sus estancias, elevados índices de complejidad, los gráficos de accesibilidad que presentan tienen tendencia a la simetría, y por último, suelen presentar una forma radial de organizar el espacio a partir de un peristilo que actúa como centro controlador (figs. 3-4).

El segundo modelo-tipo, enunciado como Modelo B o modelo de control policéntrico, presenta como principal característica la existencia de dos o más espacios con CV superiores al resto de espacios. El resto de características que nos permiten identificar y definir este modelo son: los bajos valores de RA que presentan todas sus estancias, que no presenta un carácter radial en cuanto a su gráfico de accesibilidad se refiere, que los espacios se articulan -de forma general- a partir del peristilo y la entrada a la villa. Otras variables sobre las que profundizar en trabajos futuros podrían ser: dimensiones de la villa en relación con el modelo que presenta y secuencia cronológica de las mismas en relación con dichos modelos (figs. 5-6). 


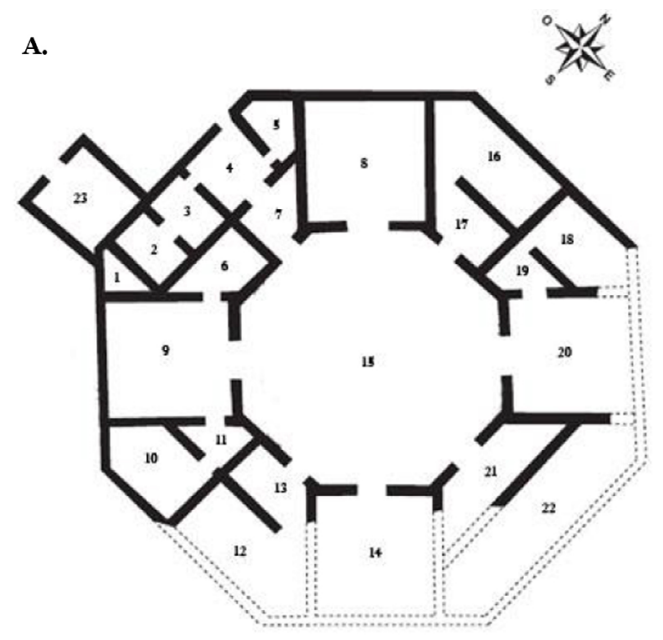

c.

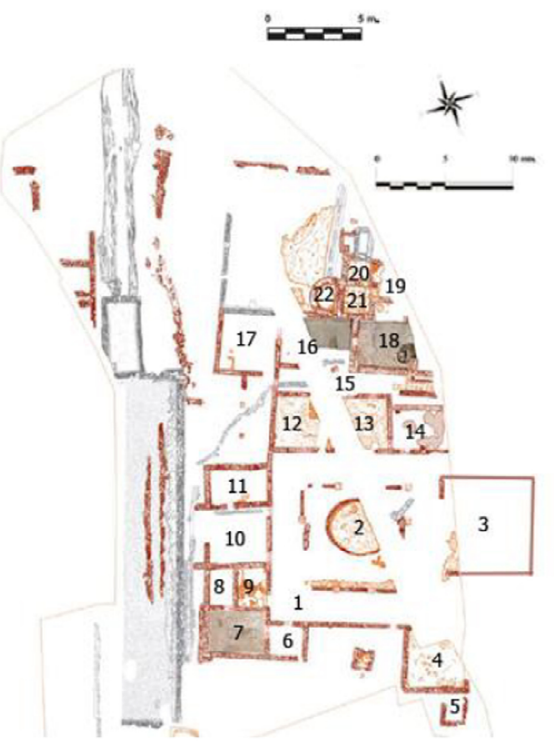

B.

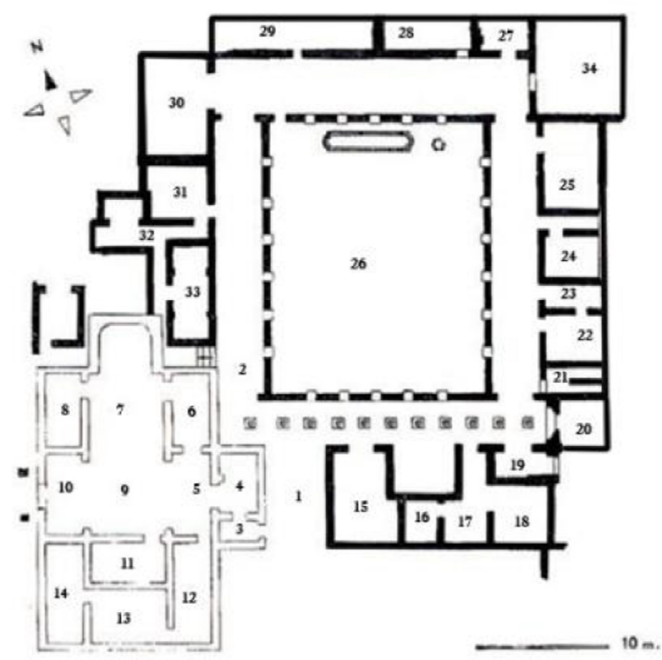

D.

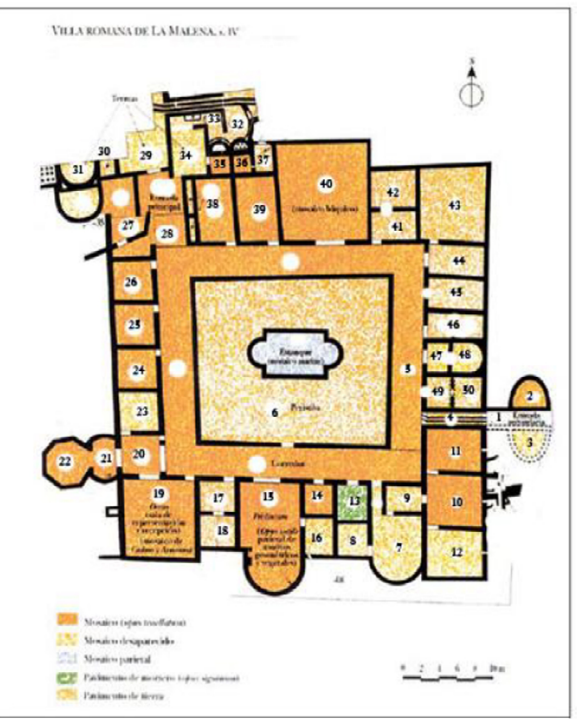

E.

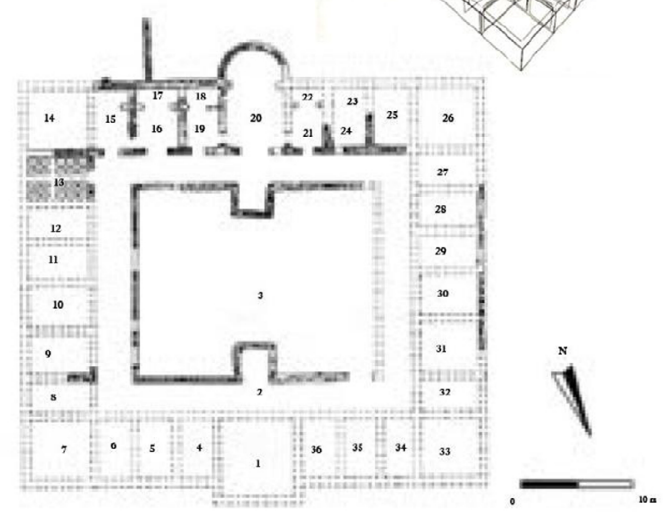

Fig. 3. Planimetrías de las villas Modelo A sobre las que se ha aplicado la sintaxis espacial. A) Horta Farrerons (Premia de Mar), a partir de Bosch, Coll y Font, 2005: 171; B)Fortunatus (Fraga), a partir de Mezquíriz, 2009: 256; C) Cornelius (L'Enova), a partir de Albiach y De Madaria, 2006: 71; D) La Malena (Azuara), a partir de Mezquíriz, 2009: 249; E) La Torrecilla (Getafe), a partir de Blasco y Lucas, 2000. 
A.

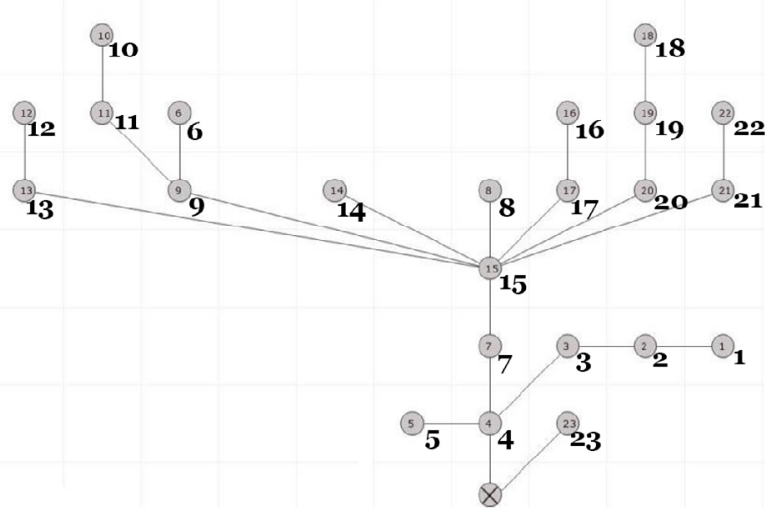

C.

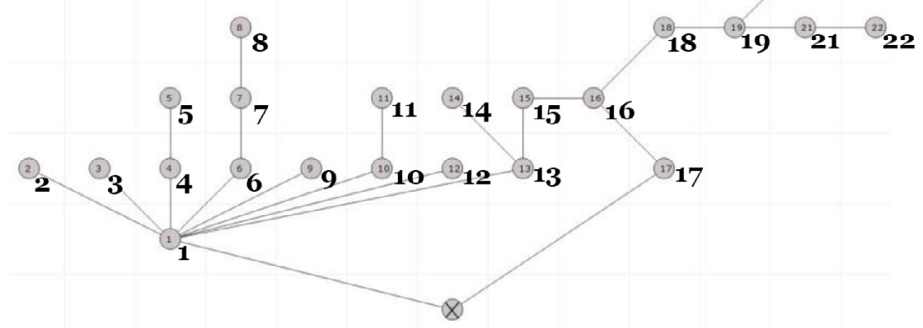

B.
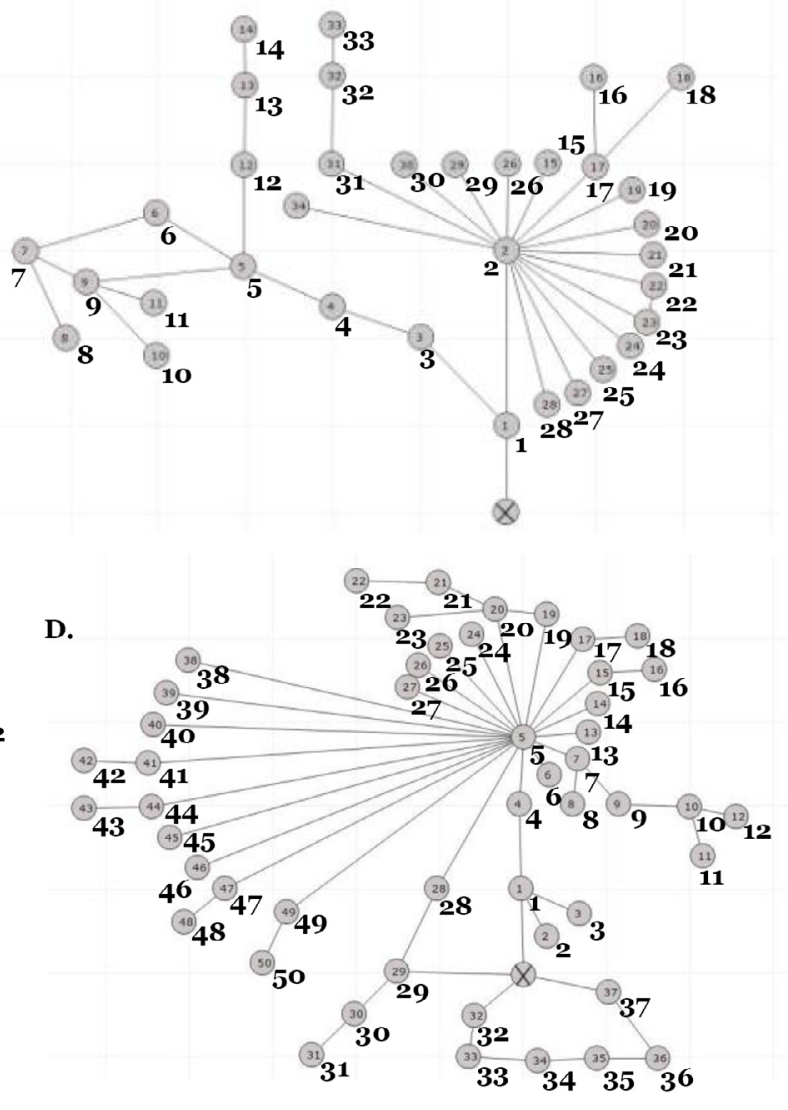

E.

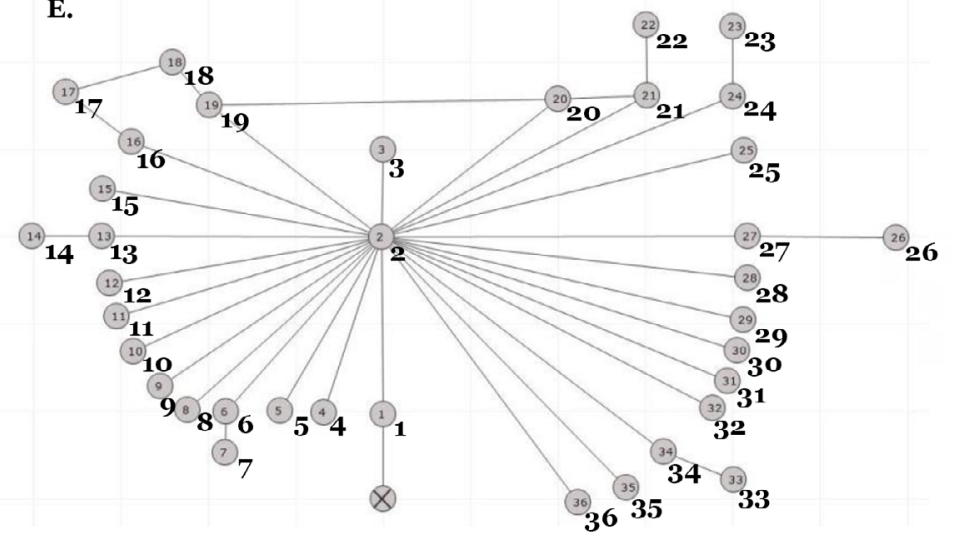

Fig. 4. Planimetrías de las villas Modelo B sobre las que se ha aplicado la sintaxis espacial. A) Torre Llauder (Mataró), a partir de Revilla, 2008: 111; B) La Dehesa (Cuevas Soria), a partir de García-Entero, 2009; C) La Olmeda (Pedrosa de la Vega), a partir de García de Paredes y Pedrosa, 2010; D) Almenara de Adaja (La Almenara de Adaja), a partir de García-Merino y Sánchez-Simón, 2004: 179; E) Pou de la Sargueta (Riba Roja del Túria), a partir de Hortelano, 2007. 
A.
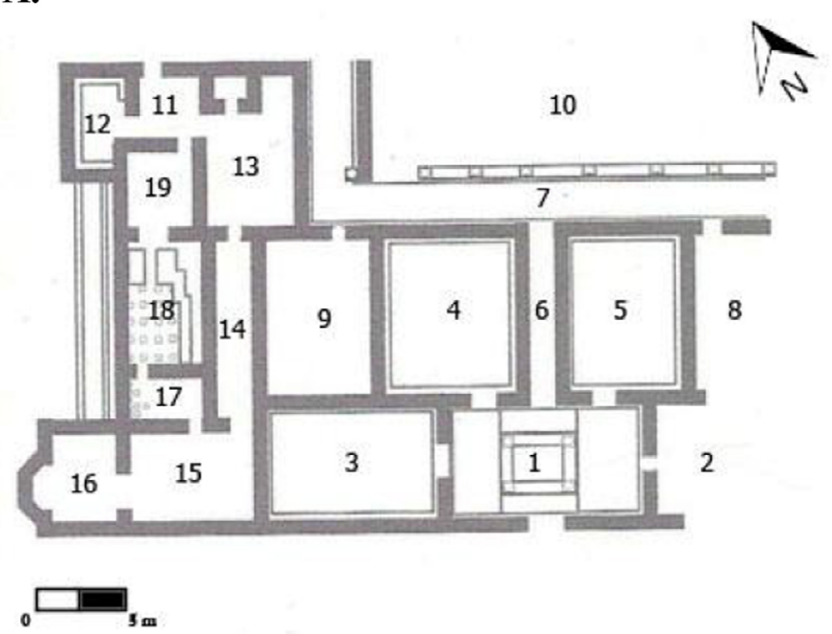

C.

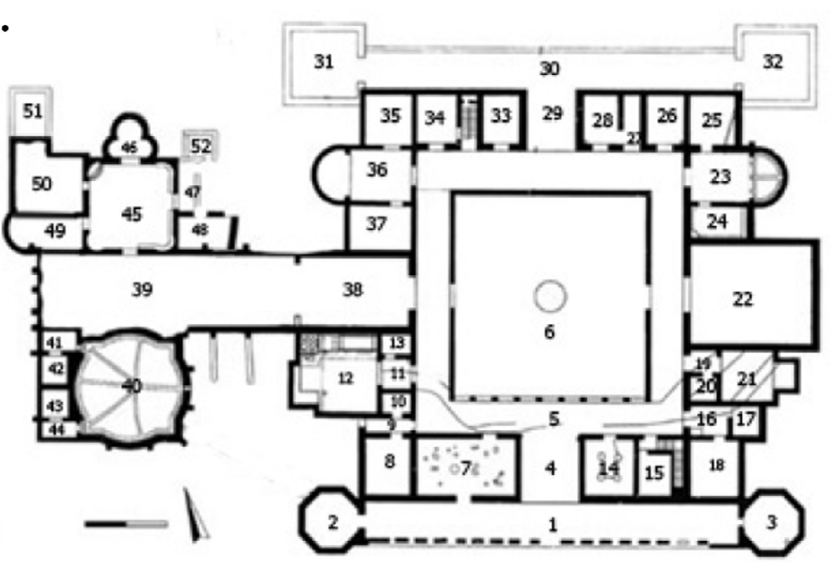

B.

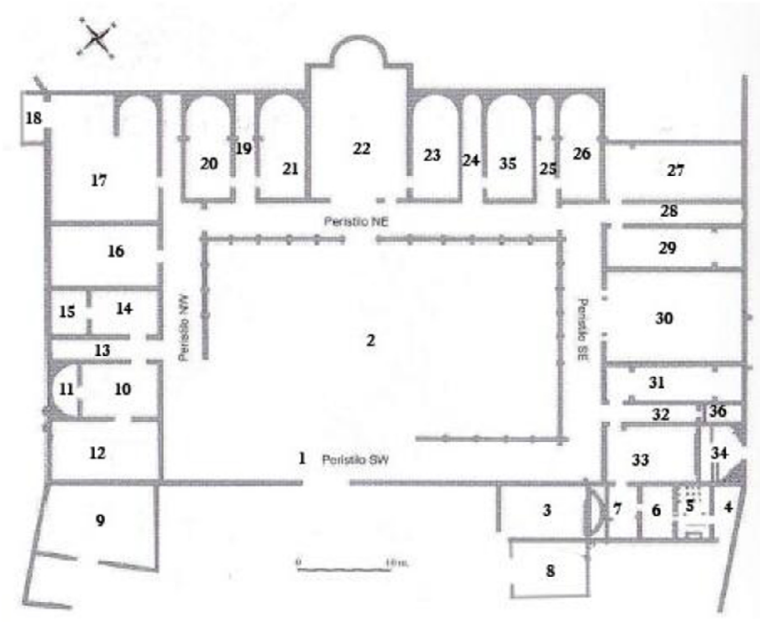

D.

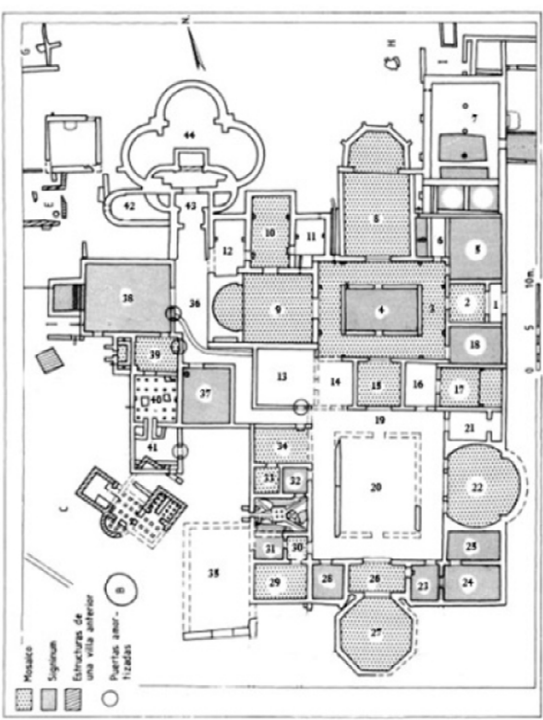

E. $\widehat{A}_{\mathrm{N}}$
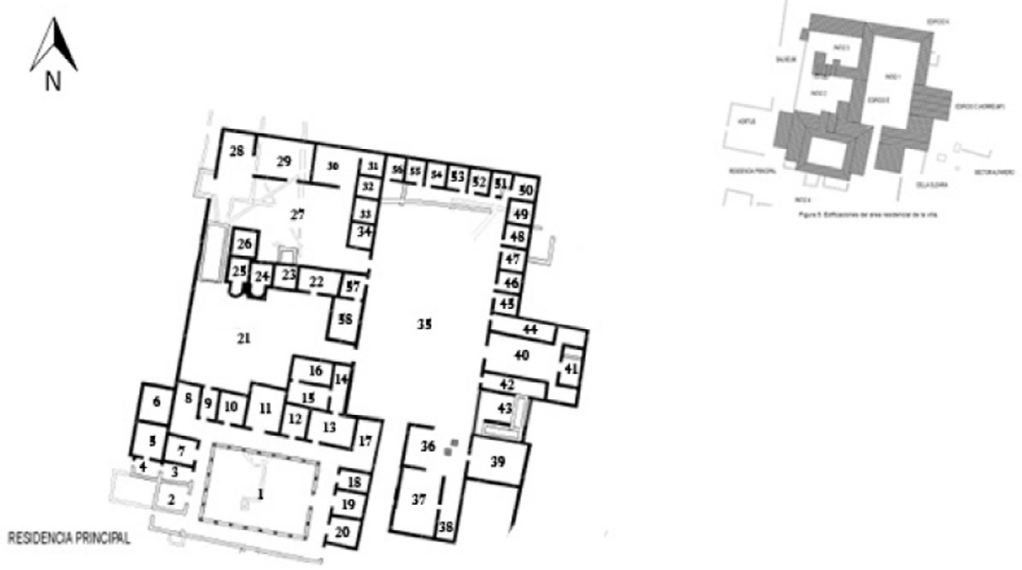

Fig. 5. Planimetrías de las villas Modelo A sobre las que se ha aplicado la sintaxis espacial. A) Horta Farrerons (Premia de Mar), a partir de Bosch, Coll y Font, 2005: 171; B) Fortunatus (Fraga), a partir de Mezquíriz, 2009: 256; C) Cornelius (L'Enova), a partir de Albiach y De Madaria, 2006: 71; D) La Malena (Azuara), a partir de Mezquíriz, 2009: 249; E) La Torrecilla (Getafe), a partir de Blasco y Lucas, 2000. 
A.

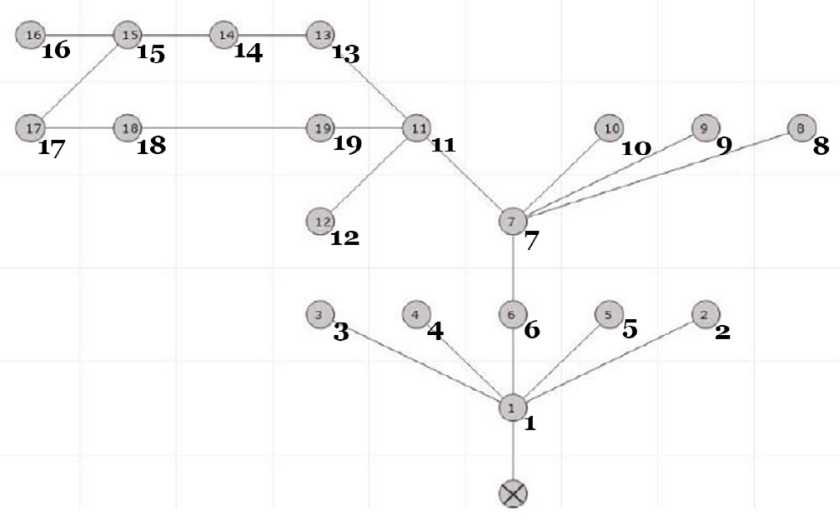

C.

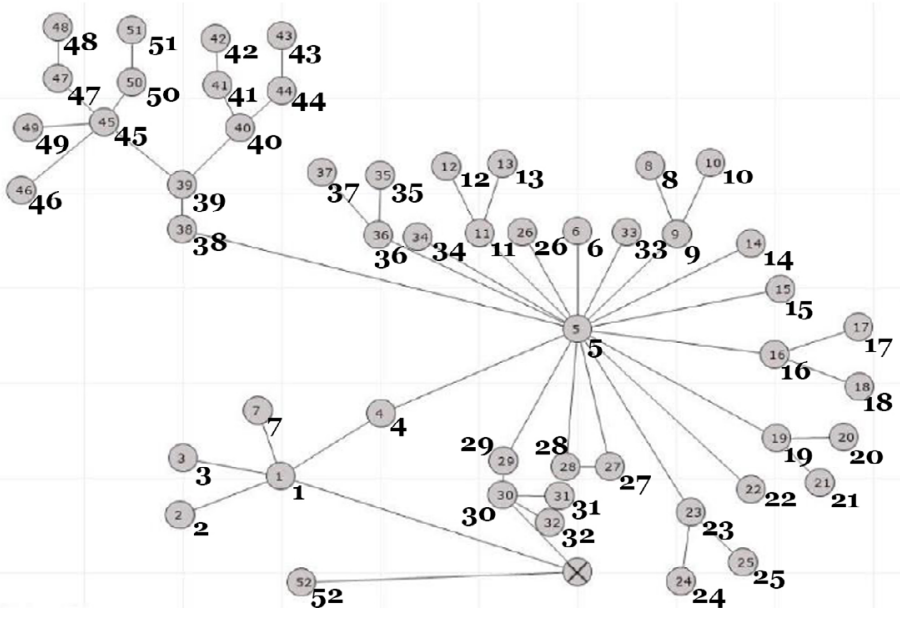

E.

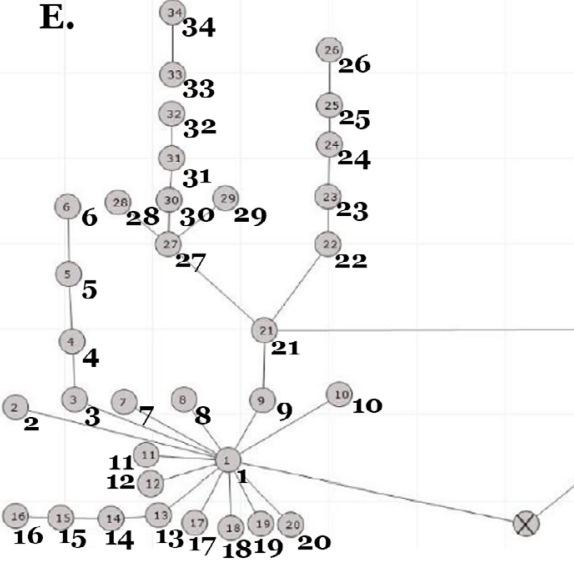

B.

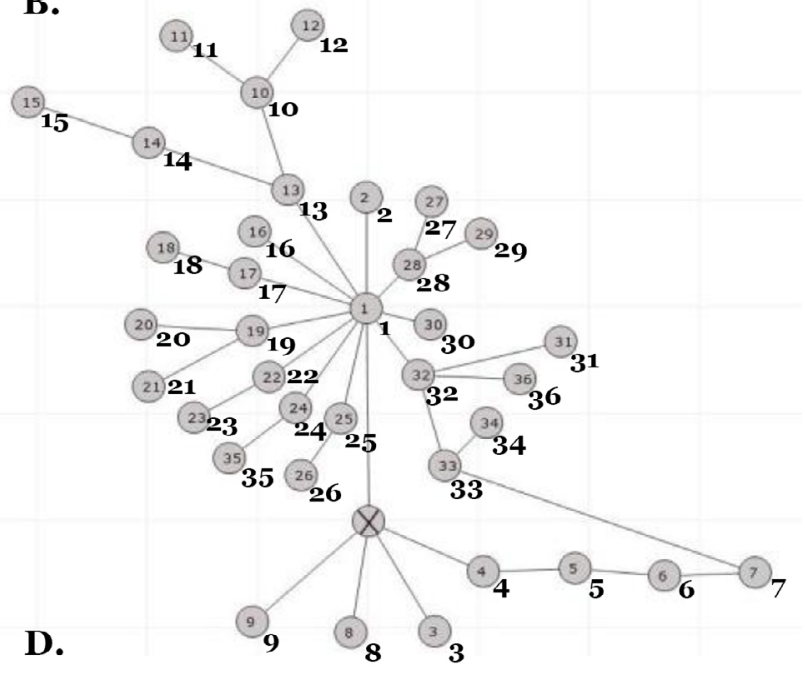

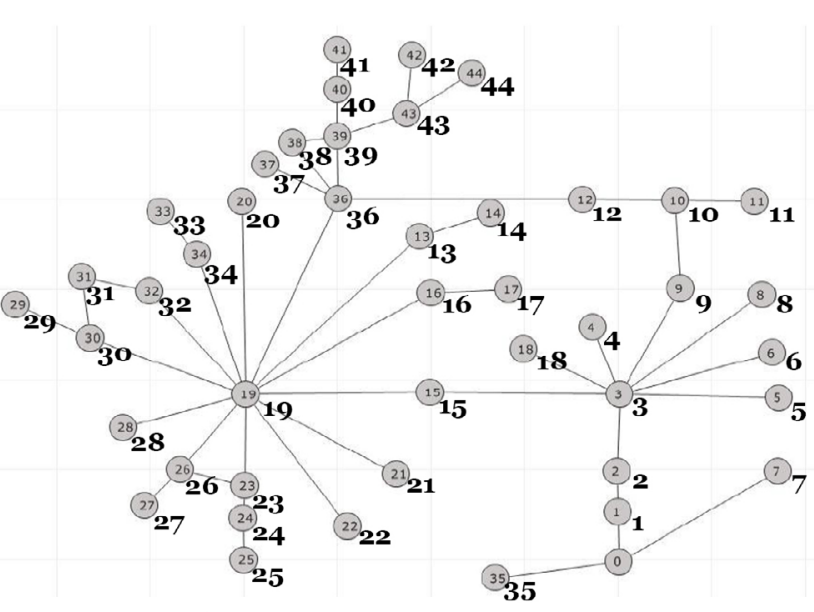

$\sqrt[35]{35}$

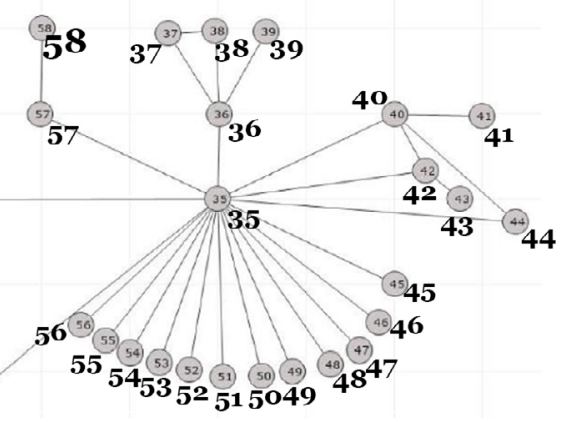

Fig. 6. Gráficos de accesibilidad de las villas analizadas correspondientes con el Modelo A. Generados a partir de la aplicación AGRAPH 3.0 desarrollada por B. Manum. A) Horta Farrerons (Premia de Mar); B) Fortunatus (Fraga); C) Cornelius (L'Enova); D) La Malena (Azuara); E) La Torrecilla (Getafe). 


\section{2. Casos de estudio}

\subsubsection{Torre Llauder (Mataró, Barcelona)}

Esta villa situada al sur de la ciudad romana de Iluro-Mataró, Barcelona- se encuentra anexa a una de las principales vías de comunicación que atraviesa Hispania en época romana: la vía Augusta (Clariana y Prevosti, 1992: 61-62). Con una superficie total de unos $670 \mathrm{~m}^{2}$ en lo que a su pars urbana se refiere. La principal transformación arquitectónica de la villa se realizará a principios del siglo III d.C., momento que mostramos en la planimetría empleada (Revilla, 2008: 109-111).

La sintaxis espacial nos ofrece dos espacios significativos que muestran un valor de control muy superior al resto: el peristilo -7- con un valor de control de 3,75, y el atrio - 1- con un valor de control de 5,50. Ambos espacios parecen los principales núcleos articuladores de la villa. Por el contrario, los valores de RA entre las diversas estancias no muestran diferencias significativas lo que muestra una estrecha convivencia entre los individuos que poblaron esta villa gestionada principalmente a partir de los espacios de control 1 y 7.

\subsubsection{Horta Farrerons (Premia de Mar, Barcelona)}

El yacimiento de Horta Farrerons se sitúa al Norte del municipio de Premia del mar a unos 200 $\mathrm{m}$ de la línea de costa actual (Bosch, Coll y Font: 2005). Con un área total de $735 \mathrm{~m}^{2}$, y situado en la zona norte del yacimiento es el edificio con mayor entidad del conjunto (Coll: 2008). Por último, en lo que hace referencia a su evolución, su segunda fase, que sería la que analizamos en este trabajo, se corresponde con el momento de actividad plena del conjunto arquitectónico iniciándose a finales del IV d.C. y llegando hasta mediados del siglo V d.C.

En cuanto a la sintaxis, tenemos un modelo de planta tipo protopanóptico con un gran espacio controlador, con un elevado CV -4,83- respecto al resto de espacios. La escasa diferenciación entre los valores de RA de las 23 estancias concuerda con la necesidad de un espacio que sirva para gestionar el control del resto de estancias. También tenemos numerosos espacios que por sus características -8, 9, 14 y 20- pueden servirnos como ejemplo de espacios óptimos para que el dominus haga ostentación de su poder como indicábamos en el apartado de metodología.

\subsubsection{Pou de la Sargueta (Riba Roja del Túria, Valencia)}

La Villa Romana del Pou de la Sargueta está situada en el Pla de Quart en el actual término municipal de Riba Roja del Turia a $13 \mathrm{~km}$ al Oeste de Valencia. Esta villa gozaría con una posición estratégica privilegiada durante época romana, ya que se sitúa la ruta de contacto de Valentia con Segobriga. Ocuparía alrededor de $3100 \mathrm{~m}^{2}$, y el análisis sintáctico espacial ha sido aplicado sobre su segunda fase, que se extendería durante todo el siglo III d.C. (Hortelano, 2007). 
Al observar el gráfico de accesibilidad vemos como esta villa cumpliría de forma fidedigna los principios ideales que definen nuestro Modelo B. Tenemos una serie de espacios -1, 21, 27 y 35 poseen un CV muy elevado en comparación con el resto de espacios, especialmente 1 y 35 , con un índice de CV 12 y 14,58 respectivamente. Asimismo observando la desviación estándar en los valores de RA vemos como apenas existe asimetría espacial lo que justifica que un patrón de convivencia tan estrecho se supla con varios espacios controladores.

\subsubsection{Cornelius (L’ènova, Valencia)}

La Villa de Cornelius, situada en el término municipal de L'Enova en la provincia de Valencia, presentaría una posición privilegiada durante época romana ya que se encontraría a escasas millas al Norte de Saetabis en una ladera de suave pendiente junto a la vía Augusta. Estaría situada en una terraza de unos $2800 \mathrm{~m}^{2}$, de los cuales $715 \mathrm{~m}^{2}$ estarían ocupados por su pars urbana sobre la que aplicaremos la sintaxis espacial en su segunda fase que arranca a mediados del siglo III y llega hasta la mitad del siglo IV d.C. (Albiach y De Madaria, 2006: 13-14).

Vemos como tenemos un único espacio con un índice de CV, 6,33, muy superior al resto -1- que funciona como centro articulador de todos los espacios de la villa. La diferencia con el resto de espacios, cuya media en el CV no llega a 1,5, es considerable, viéndose como claramente tenemos un modelo radial del resto de estancias.

\subsubsection{La Olmeda (Pedrosa de la Vega, Palencia)}

Dentro del actual término municipal del Pedrosa de la Vega, en Palencia, al Oeste del río Carrión tenemos la conocida como la Villa Romana de La Olmeda. Esta villa presentaría una posición privilegiada, ya que se situaría en el cruce de dos vías de comunicación vitales en La Meseta, entre Legio-Pallantia y Legio-Segisama. Tiene una extensión aproximada de $3145 \mathrm{~m}^{2}$ y la construcción del edificio residencia-monumental se situaría en el segundo cuarto del siglo IV d.C., produciéndose su abandono a finales del siglo V d.C. (García de Paredes y Pedrosa, 2010).

En lo referente al gráfico de accesibilidad vemos como tenemos un modelo de control policéntrico, en el que los espacios que ocupan un papel relevante son: en primer lugar el peristilo -5- con un índice de CV de 11,50; seguido de la entrada principal -1- con un índice de CV de 3,83, y la entrada secundaria -30- con un índice de CV de 2,83. Otro espacio que presenta un índice de CV significativo es una de las salas del principal conjunto termal -45- con un valor de 3,33. Vemos cómo pese a la existencia de diferentes espacios controladores, el peristilo y las entradas siguen siendo aquellos espacios donde se mitiga la estrecha convivencia, que revelan los similares valores de RA. 


\subsubsection{La Villa de La Almenara de Adaja (La Almenara de Adaja, Valladolid)}

Esta villa se encuentra situada entre los municipios actuales de Almenara y Puras a unos $15 \mathrm{~km}$ al Suroeste de la antigua ciudad de Coca. Presenta unas dimensiones de $2472 \mathrm{~m}^{2}$ en su segunda fase, que abarca desde inicios del siglo IV d.C. hasta mediados del siglo V d.C. (García-Merino y Sánchez-Simón, 2004: 182).

Vemos como en La Almenara de Adaja se cumple el denominado Modelo B, donde tenemos dos espacios controladores -3 y 19-, con unos índices de CV de 6,50 y 7,70, respectivamente. Al contrario que en otras villas con este mismo modelo, como puede ser el caso de La Olmeda, en La Almenara de Adaja no tenemos una gran diferencia, o jerarquización, entre los espacios controladores, sino que ambos presentan valores similares.

\subsubsection{La Torrecilla (Getafe, Madrid)}

La Villa Romana de La Torrecilla se encuentra en un meandro del río Manzanares a $1500 \mathrm{~m}$ al Oeste del arroyo Culebro en el término municipal actual de Getafe al Suroeste de Madrid. Tiene una extensión de $903 \mathrm{~m}^{2}$, y en nuestro caso el estudio se ha centrado en su fase más monumental, ubicada a mediados del siglo I.V. d.C. (Blasco y Lucas, 2000: 111).

Estamos ante el conjunto constructivo que presenta la menos diferenciación entre los diversos valores de RA, lo que nos indica que es el edificio, entre el conjunto de los casos de estudio, en el que la convivencia es más estrecha. Estamos una villa que representaría el prototipo ideal del Modelo A, en la que tenemos un espacio central -2-, que posee un índice de CV, 21,50, muy superior al resto de estancias.

\subsubsection{La Dehesa (Cuevas Soria, Soria)}

La Villa de La Dehesa está ubicada en el actual término municipal de Cuevas Soria a $20 \mathrm{~km}$ al Suroeste de Soria, cerca del río Izara. Con una extensión total de $2142 \mathrm{~m}^{2}$ nuestro análisis será aplicado sobre la fase principal del yacimiento, en torno al siglo I.V. d.C. (Gómez-Fernández, 2005).

En La Dehesa encontramos únicamente un espacio con un índice de CV significativo, el pasillo del peristilo -1-, con un valor de 6,45. Aunque tenemos otras estancias con valores sensiblemente elevados, como pueden ser las estancias -10-y-32-, si observamos la forma del gráfico de accesibilidad vemos como al modelo que más se aproxima es al Modelo $\mathrm{B}$, aunque siendo muy estrictos estaría a medio camino entre los modelos A y B. 


\subsubsection{Fortunatus (Fraga, Huesca)}

La Villa de Fortunatus se encuentra situada en la orilla izquierda del río Cinca, a unos $5 \mathrm{~km}$ al Norte de la actual Fraga. Esta villa ocuparía una posición privilegiada entre las vías que unían Ilerda-Celsa y Ilerda-Caesaraugusta. La sintaxis espacial será aplicada sobre la fase monumental del yacimiento, que se sitúa alrededor del siglo IV d.C. (Mezquíriz, 2009).

En lo referente al análisis sintáctico espacial vemos como estamos ante una villa cuyo modelo-tipo se aproxima al Modelo A, o protopanóptico. Tenemos un gran núcleo controlador -2-, con un índice de CV de 14,16, que articula el resto de estancias a su alrededor, siguiendo un esquema radial. Sin embargo, podemos observar como la estancia -9- también presenta un índice de CV sensiblemente elevado.

\subsubsection{La Malena (Azuara, Zaragoza)}

La Villa Romana de La Malena se encuentra en la Cuenca Media del Ebro, a unos $60 \mathrm{~km}$ al Sur de Caesaraugusta, precisamente en la calzada que une Celsa con la vía de conexión entre Caesaraugusta y Emerita Augusta. Tiene una extensión de $4030 \mathrm{~m}^{2}$, en lo que a su pars urbana se refiere. La fase que sobre la que hemos aplicado el análisis sintáctico espacial ha sido la segunda fase del yacimiento, que arranca va desde la segunda mitad del siglo I.V. d.C. hasta los inicios del siglo V d.C. (Royo, 2001).

En cuanto a los datos aportados por la sintaxis espacial, vemos como de nuevo el pasillo del peristilo -5- presenta un elevado índice de CV, 17,08. Aunque la estructuración que tenemos presente en La Malena encajaría con el Modelo A, no podemos dejar de lado el índice de CV que nos ofrece la entrada principal -1-, 2,75. Una vez más, aunque tengamos un modelo-tipo protopanóptico, la entrada vuelve a jugar un papel crucial en cuanto a la gestión del control de los espacios de la pars urbana se refiere (figs. 7-8).

\subsection{Consideraciones finales}

En lo que a la interrelación de los datos se refiere, podemos concluir que los Modelos A y B, el protopanóptico y el modelo de control policéntrico, se distribuyen al $50 \%$ respecto a la totalidad de los casos de estudio expuestos. Vemos, como por lo general, existen varias salas que funcionan como centros de control, en prácticamente la totalidad de las villas, supliendo de esta manera los estrechos niveles de convivencia, y la escasa capacidad de segregación espacial, que nos vienen reflejados en los bajos índices de RA. A partir de esta serie de modelos también confirmamos una funcionalidad de los peristilos, más allá de la clásica función cumplida por estos como meras zonas de ventilación y articulación de espacios. Esta función confirmada sería la función de vigilancia, como espacios de control de primer orden, jugando un relevante papel como entidades de control espacial, y reflejado en el elevado índice de CV que muestran prácticamente en la totalidad de los casos. 
MODELO A -Valores de RA y CV-

\begin{tabular}{|c|c|c|c|c|c|}
\hline \multirow{2}{*}{$\begin{array}{c}\mathrm{N}^{\circ} \\
\text { Unidad } \\
\text { Espacial }\end{array}$} & A. Horta Farrerons & B. Fortunatus & C. Comelius & D. La Malena & E. La Torrecilla \\
\hline & $\mathrm{RA} / \mathrm{CV}$ & $\mathrm{RA} / \mathrm{CV}$ & $\mathrm{RA} / \mathrm{CV}$ & $\mathrm{RA} / \mathrm{CV}$ & $\mathrm{RA} / \mathrm{CV}$ \\
\hline 1 & $0,41 / 0,50$ & $0,11 / 1,55$ & $0,14 / 6,33$ & $0,09 / 2,75$ & $0,06 / 1,03$ \\
\hline 2 & $0,32 / 1,50$ & $0,09 / 14,16$ & $0,23 / 0,11$ & $0,13 / 0,25$ & $0,01 / 21,50$ \\
\hline 3 & $0,24 / 0,75$ & $0,13 / 0,83$ & $0,23 / 0,11$ & $0,13 / 0,25$ & $0,06 / 0,03$ \\
\hline 4 & $0,17 / 2,50$ & $0,15 / 0,75$ & $0,22 / 1,11$ & $0,07 / 0,29$ & $0,06 / 0,03$ \\
\hline 5 & $0,26 / 0,25$ & $0,18 / 1,75$ & $0,31 / 0,50$ & $0,04 / 17,08$ & $0,06 / 0,03$ \\
\hline 6 & $0,25 / 0,33$ & $0,23 / 0,58$ & $0,21 / 0,61$ & $0,08 / 0,04$ & $0,06 / 1,03$ \\
\hline 7 & $0,13 / 0,37$ & $0,27 / 1,75$ & $0,29 / 1,50$ & $0,07 / 1,54$ & $0,12 / 0,50$ \\
\hline 8 & $0,19 / 0,12$ & $0,33 / 0,33$ & $0,38 / 0,50$ & $0,11 / 0,33$ & $0,06 / 0,03$ \\
\hline 9 & $0,16 / 1.62$ & $0,22 / 2,58$ & $0,23 / 0,11$ & $0,11 / 0,66$ & $0,06 / 0,03$ \\
\hline 10 & $0,33 / 0,50$ & $0,28 / 0,25$ & $0,22 / 1,11$ & $0,15 / 2,50$ & $0,06 / 0,03$ \\
\hline 11 & $0,24 / 1,33$ & $0,28 / 0,25$ & $0,31 / 0,50$ & $0,19 / 0,33$ & $0,06 / 0,03$ \\
\hline 12 & $0,27 / 0,50$ & $0,23 / 0,75$ & $0,23 / 0,11$ & $0,19 / 0,33$ & $0,06 / 0,03$ \\
\hline 13 & $0,18 / 1,12$ & $0,28 / 1,50$ & $0,16 / 1,61$ & $0,08 / 0,04$ & $0,06 / 1,03$ \\
\hline 14 & $0,19 / 0,12$ & $0,34 / 0,50$ & $0,25 / 0,33$ & $0,0 \mathrm{~S} / 0,04$ & $0,12 / 0,50$ \\
\hline 15 & $0,10 / 4,83$ & $0,15 / 0,05$ & $0,19 / 0,66$ & $0,08 / 1,04$ & $0,06 / 0,03$ \\
\hline 16 & $0,27 / 0,50$ & $0,21 / 0,33$ & $0,22 / 1,50$ & $0,12 / 0,50$ & $0,06 / 0,53$ \\
\hline 17 & $0,18 / 1,12$ & $0,15 / 2,05$ & $0,20 / 0,83$ & $0,08 / 1,04$ & $0,11 / 1,00$ \\
\hline 18 & $0,34 / 0,50$ & $0,21 / 0,33$ & $0,28 / 0,66$ & $0,12 / 0,50$ & $0,11 / 0,83$ \\
\hline 19 & $0,25 / 1,50$ & $0,15 / 0,05$ & $0,34 / 2,00$ & $0,08 / 0,29$ & $0,06 / 0,87$ \\
\hline 20 & $0,17 / 0,62$ & $0,15 / 0,05$ & $0,43 / 0,33$ & $0,08 / 2,04$ & $0,06 / 0,70$ \\
\hline 21 & $0,18 / 1,12$ & $0,15 / 0,05$ & $0,42 / 1,33$ & $0,11 / 1,25$ & $0,06 / 1,37$ \\
\hline 22 & $0,27 / 0,50$ & $0,15 / 0,55$ & $0,51 / 0,50$ & $0,15 / 0,50$ & $0,12 / 0,33$ \\
\hline 23 & $0,34 / 0,50$ & $0,15 / 0,55$ & & $0,12 / 0,25$ & $0,12 / 0,50$ \\
\hline 24 & & $0,15 / 0,05$ & & $0,08 / 0,04$ & $0,06 / 1,03$ \\
\hline 25 & & $0,15 / 0,05$ & & $0,0 \mathrm{~S} / 0,04$ & $0,06 / 0,03$ \\
\hline 26 & & $0,15 / 0,05$ & & $0,08 / 0,04$ & $0,12 / 0,50$ \\
\hline 27 & & $0,15 / 0,05$ & & $0,08 / 0,04$ & $0,06 / 1,03$ \\
\hline 28 & & $0,15 / 0,05$ & & $0,07 / 0,37$ & $0,06 / 0,03$ \\
\hline 29 & & $0,15 / 0,05$ & & $0,09 / 1,25$ & $0,06 / 0,03$ \\
\hline 30 & & $0,15 / 0,05$ & & $0,12 / 1,33$ & $0,06 / 0,03$ \\
\hline 31 & & $0,15 / 0,55$ & & $0,16 / 0,50$ & $0,06 / 0,03$ \\
\hline 32 & & $0,20 / 1,50$ & & $0,15 / 0,75$ & $0,06 / 0,03$ \\
\hline 33 & & $0,26 / 0,50$ & & $0,18 / 1,00$ & $0,12 / 0,50$ \\
\hline 34 & & $0,15 / 0,05$ & & $0,22 / 1,00$ & $0,06 / 1,03$ \\
\hline 35 & & & & $0,22 / 1,00$ & $0,06 / 0,03$ \\
\hline 36 & & & & $0,18 / 1,00$ & $0,06 / 0,03$ \\
\hline 37 & & & & $0,15 / 0,75$ & \\
\hline 38 & & & & $0,08 / 0,04$ & \\
\hline 39 & & & & $0,08 / 0,04$ & \\
\hline 40 & & & & $0,08 / 0,04$ & \\
\hline 41 & & & & $0,08 / 1,04$ & \\
\hline 42 & & & & $0,12 / 0,50$ & \\
\hline 43 & & & & $0,12 / 0,50$ & \\
\hline 44 & & & & $0,08 / 1,04$ & \\
\hline 45 & & & & $0,08 / 0,04$ & \\
\hline 46 & & & & $0,08 / 0,04$ & \\
\hline 47 & & & & $0,0 \mathrm{~S} / 1,04$ & \\
\hline 48 & & & & $0,12 / 0,50$ & \\
\hline 49 & & & & $0,08 / 1,04$ & \\
\hline 50 & & & & $0,12 / 0,50$ & \\
\hline
\end{tabular}

Fig. 7. Valores de asimetría relativa y valores de control de las villas correspondientes al Modelo A. 
MODELO B -Valores de RA y CV-

\begin{tabular}{|c|c|c|c|c|c|}
\hline \multicolumn{6}{|c|}{ MODELO B -Valores de RA y CV- } \\
\hline \multirow{2}{*}{$\begin{array}{l}\mathrm{N}^{\circ} \text { Unidad } \\
\text { Espacial }\end{array}$} & A. Torre Llauder & B. La Dehesa & C. La Olmeda & $\begin{array}{l}\text { D. Almenara de } \\
\text { Adaja }\end{array}$ & $\begin{array}{l}\text { E. Pou de la } \\
\text { Sargueta }\end{array}$ \\
\hline & $\mathrm{RA} / \mathrm{CV}$ & $\mathrm{RA} / \mathrm{CV}$ & $\mathrm{RA} / \mathrm{CV}$ & $\mathrm{RA} / \mathrm{CV}$ & $\mathrm{RA} / \mathrm{CV}$ \\
\hline 1 & $0,24 / 5,50$ & $0,05 / 6,45$ & $0,10 / 3,83$ & $0,17 / 0,83$ & $0,07 / 12,00$ \\
\hline 2 & $0,35 / 0,16$ & $0,10 / 0,08$ & $0,14 / 0,20$ & $0,13 / 0,62$ & $0,10 / 0,07$ \\
\hline 3 & $0,35 / 0,16$ & $0,14 / 0,20$ & $0,14 / 0,20$ & $0,10 / 6,50$ & $0,10 / 0,57$ \\
\hline 4 & $0,35 / 0,16$ & $0,13 / 0,70$ & $0,08 / 0,25$ & $0,14 / 0,12$ & $0,13 / 1,00$ \\
\hline 5 & $0,35 / 0,16$ & $0,17 / 1,00$ & $0,05 / 11,50$ & $0,14 / 0,12$ & $0,16 / 1,50$ \\
\hline 6 & $0,19 / 0,36$ & $0,21 / 1,00$ & $0,08 / 0,05$ & $0,14 / 0,12$ & $0,20 / 0,5$ \\
\hline 7 & $0,16 / 3,75$ & $0,17 / 0,83$ & $0,14 / 0,20$ & $0,26 / 0,33$ & $0,10 / 0,07$ \\
\hline 8 & $0,26 / 0,20$ & $0,14 / 0,20$ & $0,12 / 0,33$ & $0,14 / 0,12$ & $0,10 / 0,07$ \\
\hline 9 & $0,26 / 0,20$ & $0,14 / 0,20$ & $0,08 / 2,05$ & $0,13 / 0,45$ & $0,07 / 0,32$ \\
\hline 10 & $0,26 / 0,20$ & $0,13 / 2,33$ & $0,12 / 0,33$ & $0,13 / 2,00$ & $0,10 / 0,07$ \\
\hline 11 & $0,17 / 2,20$ & $0,19 / 0,33$ & $0,08 / 2,05$ & $0,17 / 0,33$ & $0,10 / 0,07$ \\
\hline 12 & $0,28 / 0,25$ & $0,19 / 0,33$ & $0,12 / 0,33$ & $0,11 / 0,53$ & $0,10 / 0,07$ \\
\hline 13 & $0,23 / 0,75$ & $0,09 / 0,91$ & $0,12 / 0,33$ & $0,10 / 1,07$ & $0,10 / 0,57$ \\
\hline 14 & $0,30 / 0,83$ & $0,14 / 1,33$ & $0,08 / 0,05$ & $0,15 / 0,50$ & $0,13 / 1,00$ \\
\hline 15 & $0,36 / 2,00$ & $0,19 / 0,50$ & $0,08 / 0,05$ & $0,0 \mathrm{~S} / 0,20$ & $0,16 / 1,50$ \\
\hline 16 & $0,47 / 0,33$ & $0,10 / 0,0 \mathrm{~S}$ & $0,08 / 2,05$ & $0,10 / 1,07$ & $0,20 / 0,50$ \\
\hline 17 & $0,37 / 0,83$ & $0,10 / 1,08$ & $0,12 / 0,33$ & $0,15 / 0,50$ & $0,10 / 0,07$ \\
\hline 18 & $0,30 / 1,00$ & $0,15 / 0,50$ & $0,12 / 0,33$ & $0,14 / 0,12$ & $0,10 / 0,07$ \\
\hline 19 & $0,24 / 0,75$ & $0,10 / 2,08$ & $0,08 / 2,05$ & $0,06 / 7,70$ & $0,10 / 0,07$ \\
\hline 20 & & $0,15 / 0,33$ & $0,12 / 0,33$ & $0,11 / 0,07$ & $0,10 / 0,07$ \\
\hline 21 & & $0,15 / 0,33$ & $0,12 / 0,33$ & $0,11 / 0,07$ & $0,06 / 1,30$ \\
\hline 22 & & $0,10 / 1,08$ & $0,08 / 0,05$ & $0,11 / 0,07$ & $0,09 / 0,75$ \\
\hline 23 & & $0,15 / 0,50$ & $0,08 / 2,05$ & $0,10 / 0,91$ & $0,12 / 1,00$ \\
\hline 24 & & $0,10 / 1,0 \mathrm{~S}$ & $0,12 / 0,33$ & $0,14 / 1,33$ & $0,15 / 1,00$ \\
\hline 25 & & $0,10 / 1,0 \mathrm{~S}$ & $0,12 / 0,33$ & $0,19 / 0,50$ & $0,18 / 1,50$ \\
\hline 26 & & $0,15 / 0,50$ & $0,08 / 0,05$ & $0,10 / 1,41$ & $0,22 / 0,50$ \\
\hline 27 & & $0,15 / 0,33$ & $0,08 / 0,55$ & $0,15 / 0,33$ & $0,09 / 2,75$ \\
\hline $2 s$ & & $0,10 / 2,0 \mathrm{~S}$ & $0,08 / 0,55$ & $0,11 / 0,07$ & $0,12 / 0,25$ \\
\hline 29 & & $0,15 / 0,33$ & $0,08 / 0,30$ & $0,15 / 0,33$ & $0,12 / 0,25$ \\
\hline 30 & & $0,10 / 0,0 \mathrm{~S}$ & $0,10 / 2,83$ & $0,10 / 1,57$ & $0,11 / 0,75$ \\
\hline 31 & & $0,14 / 0,25$ & $0,14 / 0,25$ & $0,15 / 0,83$ & $0,15 / 1,00$ \\
\hline 32 & & $0,08 / 2,41$ & $0,14 / 0,25$ & $0,10 / 0,57$ & $0,18 / 1,00$ \\
\hline 33 & & $0,13 / 1,75$ & $0,08 / 0,05$ & $0,15 / 0,50$ & $0,21 / 1,50$ \\
\hline 34 & & $0,18 / 0,33$ & $0,08 / 0,05$ & $0,10 / 1,07$ & $0,25 / 0,50$ \\
\hline 35 & & $0,15 / 0,50$ & $0,12 / 0,33$ & $0,26 / 0,33$ & $0,05 / 14,58$ \\
\hline 36 & & $0,14 / 0,25$ & $0,08 / 2,05$ & $0,08 / 2,32$ & $0,08 / 2,05$ \\
\hline 37 & & & $0,12 / 0,33$ & $0,13 / 0,20$ & $0,12 / 0,75$ \\
\hline 38 & & & $0,07 / 0,38$ & $0,12 / 0,45$ & $0,12 / 0,75$ \\
\hline 39 & & & $0,09 / 1,03$ & $0,12 / 1,53$ & $0,12 / 0,25$ \\
\hline 40 & & & $0,12 / 1,33$ & $0,16 / 1,25$ & $0,08 / 1,8 S$ \\
\hline 41 & & & $0,15 / 1,33$ & $0,21 / 0,50$ & $0,12 / 0,25$ \\
\hline 42 & & & $0,19 / 0,50$ & $0,20 / 0,33$ & $0,09 / 1,30$ \\
\hline 43 & & & $0,19 / 0,50$ & $0,16 / 2,25$ & $0,12 / 0,33$ \\
\hline 44 & & & $0,15 / 1,33$ & $0,20 / 0,33$ & $0,09 / 0,30$ \\
\hline 45 & & & $0,11 / 3,33$ & & $0,09 / 0,05$ \\
\hline 46 & & & $0,15 / 0,20$ & & $0,09 / 0,05$ \\
\hline 47 & & & $0,15 / 1,20$ & & $0,09 / 0,05$ \\
\hline 48 & & & $0,19 / 0,50$ & & $0,09 / 0,05$ \\
\hline 49 & & & $0,15 / 0,20$ & & $0,09 / 0,05$ \\
\hline 50 & & & $0,15 / 1,20$ & & $0,09 / 0,05$ \\
\hline 51 & & & $0,19 / 0,50$ & & $0,09 / 0,05$ \\
\hline 52 & & & $0,17 / 0,33$ & & $0,09 / 0,05$ \\
\hline 53 & & & & & $0,09 / 0,05$ \\
\hline 54 & & & & & $0,09 / 0,05$ \\
\hline 55 & & & & & $0,09 / 0,05$ \\
\hline 56 & & & & & $0,09 / 0,05$ \\
\hline 57 & & & & & $0,09 / 1,05$ \\
\hline 58 & & & & & $0,12 / 0,50$ \\
\hline
\end{tabular}

Fig. 8.Valores de asimetría relativa y valores de control de las villas correspondientes al Modelo B. 
Sin embargo, existe un aspecto que debemos destacar: las limitaciones propias de la sintaxis espacial al ser aplicada a conjuntos constructivos determinados, como pueden ser las termas, ciertos complejos parciales de las villas que no se encuentran excavadas en su totalidad, etc. El hecho de que la sintaxis espacial tan solo pueda ser aplicada sobre villas excavadas en su totalidad, reduce significativamente el número de casos de estudio, por lo que debemos contar en todo momento con que en ningún caso contaremos con la totalidad de los casos de estudio reales. Otro problema es la identificación de las estructuras de la villa con una fase u otra del yacimiento, pudiendo llegar a considerar dos estructuras que pertenecen a dos fases diferentes como pertenecientes a un mismo momento. Siempre debemos ser conscientes de este hecho y ver nuevas formas que nos permitan la interrelación de los datos de esta serie de emplazamientos con los datos que nos ofrece la sintaxis espacial.

En conclusión, la sintaxis espacial se ha revelado como una metodología interesante y útil, ya que al permitirnos expresar cuantitativamente relaciones espaciales, que anteriormente eran expresadas en términos relativos en función de un patrón de idealidad, nos permite establecer una nueva forma de estudio menos relativa. Sin embargo, donde realmente la sintaxis espacial se presenta como una metodología interesante es en la interrelación de sus datos con los extraídos partir de diversos estudios de tipo histórico-arqueológicos. Es a partir de este hecho del que se ha extraído una reflexión, que si bien puede parecer secundaria, desde nuestro punto de vista tiene una relevancia muy importante: las perspectivas de futuro de los estudios interdisciplinares, en este caso la aplicación de técnicas y métodos propios de la Arquitectura a la Arqueología. En muchas ocasiones no nos detenemos a reflexionar acerca del crecimiento que ha supuesto a nuestro conocimiento sobre las sociedades del pasado las aportaciones de técnicas y métodos de otras disciplinas y ciencias a la Arqueología. En nuestra opinión, el futuro de la Arqueología depende en gran medida de la capacidad de la misma para explorar métodos y técnicas propios de otras disciplinas que nos permitan aumentar nuestros conocimientos sobre las sociedades del pasado, donde la sintaxis espacial es tan solo un ejemplo del amplio mundo técnico que nos queda por explorar. 


\section{BIBLIOGRAFÍA}

Albiach, R. y De Madaria, J. L. (2006).La villa de Cornelius (L'Enova, Valencia). Valencia.

Bermejo, J. (2009). Leyendo los espacios: una aproximación crítica a la sintaxis espacial como herramienta de análisis arqueológico. Arqueología de la Arquitectura, 6, 47-62.

Bermejo, J. (2013). Análisis social de la Arquitectura Doméstica Romana en la región del Alto Duero: una aproximación sintácticoespacial. En I. Grau y S. Gutiérrez (Eds.), De la Estructura Doméstica al Espacio Social. Lecturas arqueológicasdel uso social del espacio (pp. 141154). Alicante: Universidad de Alicante.

Bermejo, J.(2014).Arqueología Biopolítica. La sintaxis espacial de la arquitectura doméstica romana en la Meseta Oriental. Madrid: La Ergastula.

Blasco, M. C.y Lucas, M. R.(2000). Elyacimiento de la Torrecilla: de "villa" a "tugurium". Madrid: Departamento de Prehistoria y Arqueología.

Bosch, M.; Coll, R. y Font, J.(2005). La vil.la romana de Can Farrerons (Premià de Mar, Maresme). Resultats de les darreres intervencions. Tribuna d'Arqueologia 20012002, 167-188.

Bravo, G. (2013). ¿Crisis del Imperio romano? Desmontando un tópico historiográfico.Vínculos de Historia, 2, 13-26.

Brogiolo, G. P. y Chavarría, A. (2008). El final de las villas y las transformaciones del territorio rural en Occidente (siglos V-VIII). En
C. Fernández; F. Gil y V. García-Entero (Eds.), Las villae tardorromanas en el occidente del Imperio: arquitectura y función. IV Coloquio Internacional de Arqueología en Gijón (pp. 193-213). Gijón: Universidad de Gijón.

Burillo, F. (2007). Los Celtíberos. Etnias y estados. Barcelona: Crítica.

Chavarría, A. (2006). Villas en Hispania durante la Antigüedad tardía. En A. Chavarría; G. P. Brogiolo y J. Arce (Eds.), Villas Tardoantiguas en el Mediterráneo Occidental. Anejos de AEspA XXXIX (pp. 17-35). Madrid: CSIC.

Chavarría, A. (2007). El final de las villae en Hispania: (siglos IV-VII d.C.). Turnhout: Brepols Pub.

Clariana, J. F. y Prevosti, M. (1992). Aproximació a l'estudi de l'antiguitat tardana a la vil·la romana de Torre Llauder (Mataró). Sessió d'Estudis Mataronins, 9, 61-86.

Coll, R. (2008). Les darreres novetats arqueològiques a Premià de Mar. Sessió d'Estudis Mataronins, 25, 209-232.

Foucault, M.(1984).Vigilar y castigar: el nacimiento de la prisión. México: Siglo XXI.

García-Entero, V. (2009). La investigación de las villae romanas de la Meseta. En J-R. González Pérez; M. Prevosti y V. Revilla (Eds.), Actes del Simposi: Les vil·les romanes a la Tarraconense, Vol. II (pp. 27-47). Barcelona: ICAC. 
García-Merino, C. y Sánchez-Simón, M. (2004). De nuevo acerca de la villa romana de la Almenara de Adaja (Valladolid): excavaciones de 1998 a 2002. AEspa, 77, 177-195.

García De Paredes, A. y Pedrosa, I. G.(2010). Villa romana de La Olmeda, $P H, 73,88-111$.

Gómez-Fernández, F. J. (2005). Poblamiento, ruralización e invasiones bárbaras en la Meseta Norte: el poblamiento en la provincia de Soria en el siglo V d.C. Hispania Antiqua, 29, 193-213.

Grahame, M. (2000). Reading Space: Social interactions and Identity in the Houses of Roman Pompeii. Oxford: British Archaeological Reports Limited.

Hillier, B. (1996). Space is the machine: a configurational theory of architecture. Cambridge: Cambridge University Press.

Hillier, B. y Hanson, J. (1984). The Social Logic of Space. Cambridge: Cambridge University Press.

Hortelano, I. (2007). El "Pou de la Sargueta" (Riba-Roja de Túria, Valencia). Una villa en el territorio de Valentia. Lucentum, XXVI, 115-126.

Kent, S. (1990). A cross-cultural study of segmentation, architecture, and the use ofspace, en S. Kent (Ed.),Domestic Architecture and the Use of Space. An Interdisciplinary cross-cultural study (pp. 127-152). Cambridge: Cambridge University Press.

Lefebvre, H. (1991). The Production of Space, Oxford: Blackwell.
Manum, B. (2005). AGRAPH. Software for Drawing and Calculating Space Syntex Graphs. En A. Van Nees (Ed.), Proceedinds of the 5th Space Syntax Symposium, June 2005 (pp. 96103). Amsterdam.

Mezquíriz, M. A. (2009). Las "villae" tardorromanas del Valle del Ebro.Trabajos de arqueología Navarra, 21, 199-272

Raporport, A. (1982). The Meaning of the built environment: a non verbal communication approach. Arizona: University of Arizona Press.

Revilla, V. (2008). La villa y la organización del espacio rural en el litoral central de Cataluña: implantación y evolución de un sistema de poblamiento. En J-R. González Pérez; M. Prevosti y V. Revilla (Eds.), Actes del Simposi: Les vil·les romanes a la Tarraconense, Vol. I (pp. 99-123). Barcelona: ICAC.

Royo, J. I.(2001). El conjunto arqueológico de la villa romana de La Malena (Azuara, Zaragoza). En G. Fatás y M. V. Escribano (Eds.), La antigüedad Tardía en Aragón, Vol. 20 (pp. 4657).Zaragoza: Caja de Ahorros de la Inmaculada Zaragoza.

Uribe, P. (2008).La edilicia doméstica urbana en el nordeste de la Península Ibérica (ss. I a.C. - III d.C.).Tesis doctoral depositada en la Universidad de Zaragoza. Zaragoza: Universidad de Zaragoza. 